\title{
University Hospital Struck Deaf and Silent by Lightning: Lessons to Learn
}

\author{
Fabrice Dami, MD, MBA; Pierre-Nicolas Carron, MD; Bertrand Yersin, MD; \\ Olivier Hugli, MD
}

\section{ABSTRACT}

We describe how an electromagnetic wave after a lightning strike affected a university hospital, including the communication shutdown that followed, the way it was handled, and the lessons learned from this incident. (Disaster Med Public Health Preparedness. 2015;9:440-443)

Key Words: lightning struck, electromagnetic wave, communication shutdown

$\mathrm{T}$ he literature has abundant examples of natural or human-generated disasters as well as the hospital preparedness and related training necessary to face those kinds of events. Less frequent are reports on in-hospital incidents and their consequences, in particular, lightning strikes. Most of these incidents are reported in local newspapers only. We describe here a lightning strike in the proximity of a university hospital that disabled all landlines and paging communications in 2007, the way the incident was managed, and the lessons to be learned.

\section{NARRATIVE}

The Lausanne University Hospital is a tertiary medical center with about 1500 beds. It is located within a city of 140000 inhabitants in the western part of Switzerland and serves a population area of 300000 . The hospital is a complex with 6 main units (Figure 1). In 2007, telecommunication within the hospital relied on copper (coax cables) landlines and a paging system, including the in-hospital Cardiac Arrest Team Call System. There was no internal mobile phone network, except for private ones (personal ownership), which were only partially effective because of the lack of internal antennas.

At that time the hospital already had a dedicated internal incident and disaster plan as well as a command-and-control organization staffed by team members who received alarms by the paging system. The hospital also had special landlines that were not part of the hospital network routing (redundant); these were based on a different central exchange and were effective between the hospital's central call center, the hospital's central command control center, the state's command and control center, local firefighters, and police services.
On May 21, 2007, at 8:29 pm, a storm hit the city of Lausanne and its surrounding districts with 220 lightning strikes over a period of 40 minutes. One struck close to the hospital. The chronology of the incident is detailed in Table 1 .

\section{DISCUSSION}

The hospital was not directly struck by lightning, such as the event previously reported in Belgium. ${ }^{1}$ However, the electromagnetic wave after the strike seriously damaged all 3 telephone exchange centers (indirect impact), burning 25 sensitive connective cards; thus, $95 \%$ of the 8500 hospital phones were out of order. The wave did not affect the power supply or the computer network. The state emergency dispatch center, which used the same technical center for communication, had 2 lines that were not seriously damaged by the incident. Neither the hospital nor the telecommunications provider had sufficient replacement cards on hand to repair the hospital network. The time of the incident, during the evening, is typically when activity in the hospital is less intense.

One critical situation occurred in the pediatric ward, when a patient had a massive hemorrhage 4 days after a tonsillectomy. The nurse in charge of the patient sent all staff present in the ward to get help (on-call pediatrician, on-call anesthetist), to the blood bank, and to inform the operating room to get ready. The situation was immediately life threatening. There was an increased delay of 15 minutes to take the patient to the operating room but no adverse consequences for the patient.

\section{What Are the Necessary Options and Requirements to Handle Such an Incident?}

Most hospitals are equipped with lightning rods; however, these structures are helpful only in the case 
Map of the Bugnon Hospital Campus.

\section{MAP OF THE BUGNON HOSPITAL CAMPUS}

This simplified map only shows the buildings in the Bugnon hospital campus where adult patients may be hospitalised.

For more information, go to www.chuv.ch, heading Patients et familles.

$$
\begin{aligned}
& \text { i Reception / Information } \\
& \text { (11) Cafeterias } \\
& \text { N Pursery }
\end{aligned}
$$

$\mathrm{P}$ i Disabled parking

I. M2 stations

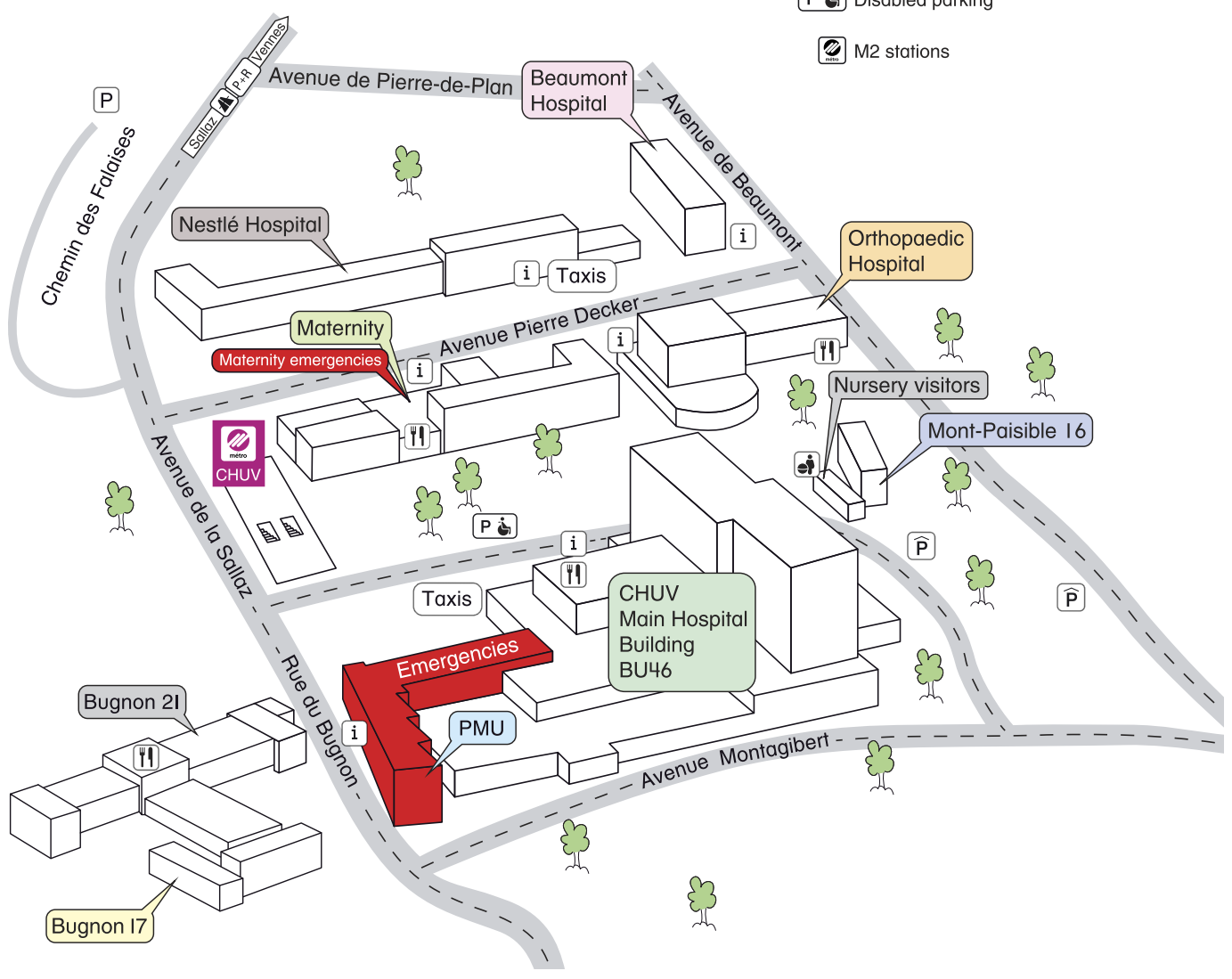

of a direct lightning impact or strike (3\% of incidents). In our situation, the incident was caused by an electromagnetic wave after a distant strike (such as in $75 \%$ of incidents) and propagated through the multiplicity of copper phoneline connections between the hospital buildings and the central exchange center. For hospitals still using this technology, the necessary options and/or requirements to face such a risk are (1) keep the copper lines and equip every phone (or group of phones) with protection against overtension, which is very costly; (2) review the copper line network to avoid telephone line curls, though hospital networks are so dense that this may not be a realistic solution; (3) migrate the copper network to a computer network (with fiberglass optics), which would not be conductive and, thus, would be resistant to lightning strikes and electromagnetic waves; or (4) do nothing. The additional advantage of the migration from copper to the fiberglass option relies on the redundancy of the optical fibers between buildings and between floors.

\section{Cost of the Incident}

The cost of the incident was CHF 230000 (about US \$191 800) for the hardware and the technical services from the private telecommunications company. The cost for additional security personnel from a private company was CHF 13000 (about US $\$ 10800$ ). Therefore, the total cost was CHF 243000 (US \$202600), but this amount does not include the additional working hours of the hospital staff. In France, for 


\section{TABLE 1}

\section{Chronology of the Lightning Strike Incident}

May 21, 2007

8:30 pm: The hospital's central call center informs the national telecommmunications operator, the head of the call center, and the head of hospital technical services that the hospital has lost all landlines and the internal paging system. There was no loss of electrical power and no computer system breakdown was observed.

8:35 pm: The head of the central command team (emergency department's chief) is informed by the call center on his personal mobile phone; he returns immediately to the hospital to lead the central command team and center.

8:50 pm: The hospital's central call center confirms that the special landlines dedicated to the hospital's central command team are in service.

8:55 pm: The head of hospital security, the head of the technical services department, and the head of general direction are informed of the incident by personal mobile phone.

8:55 pm: The first measures are decided: the general use of personal mobile phones is suggested, ideally near building windows to allow better-quality transmission. Security personnel, equipped with radios and mobile phones, are sent to strategic sites (the main reception area of the emergency department, the central command team room, the central call center, the intensive care unit, the operating room) and to all major buildings (the orthopedics hospital, the women's hospital, the infectious diseases hospital, the rehabilitation hospital) to inform personnel on duty of the incident.

9:00 pm: A major in-hospital incident is declared: personnel from the central command team and more security agents are called at home and are expected to be on site in the next 20 minutes.

9:30 pm: The head of emergency, leading the central command team, decides to dispatch 13 more security agents to strategic points within the main building of the hospital (one on each floor).

9:30 pm: The Swisscom telecommunications provider arrives on-site: 5 net cards and 28 connective cards are out of service in the 2 central units. In addition, $90 \%$ of the landlines in the main hospital building and $100 \%$ in the rehabilitation hospital are out of order.

10:00 pm: Some repair has been performed, and other required replacement pieces are being shipped from central Switzerland (130 km, a 2-hour drive).

May 22, 2007

3:20 am: The replacement pieces arrive and repair work is in progress.

3:50 am: In the main building, $70 \%$ of the landlines are functional.

5:00 am: The in-hospital cardiac arrest team call number is once again functional.

5:20 am: The central command team decides to cancel the elective surgery program starting at 7:00 am.

7:00 am: The central command team and the general director of the hospital decide to maintain the elective surgery program. A short communiqué about the incident is transmitted to the local media and on the hospital intranet; the local population is asked to not to call the hospital.

7:30 am: Security personnel are placed in front of the main buildings to inform incoming workers about the situation. The new net cards and connective cards arrive from central Switzerland and are installed: 500 more phone lines are functional again.

11:40 am: All landlines are functional in the main building.

12:00 pm: The central command team and the general director declare the end of the major incident.

example, lightning is responsible for $11 \%$ of all of the costs reimbursed by insurance companies to hospitals after a similar unlikely event. ${ }^{2}$ This incident confirms the need for lightning protection, which should be considered every time a new hospital is being built.

Although such an action is not an absolute form of protection, a lightning-rod network can transform a building into a Faraday cage, thus lowering the risk of damage in case of a direct strike. This installation should not be compromised by installing additional high antennae (radios, telecommunication). Fiberglass optics and mobile phone technology, today's standards for new construction, drastically reduce the risk related to electromagnetic waves.

Interestingly, a nearby hospital was directly struck by lightning shortly before our incident. The strike did not affect telecommunications but caused a fire within the building that was quickly managed.

\section{Lessons Learned}

After the lightning-strike incident, the hospital decided to migrate the copper network to a computer network connected with fiberglass optics. As a residual risk persisted, a second decision was to deploy a redundant parallel telephone system: an internal low-power mobile phone network that replaced the paging system. The two networks (the fiberglass optic and the mobile phone network) are interoperative but are not interdependent. During an incident or during maintenance tasks, a switch from one network to the other is possible and effective.

Fire, loss of power, and the complete or partial loss of telecommunication are major risks for hospitals. Plans should exist for such events, as they do for multiple-case-casualties and nuclear, radiological, biological, chemical, and explosive (NRBCE) disasters, and staff should be fully trained for any of these internal "act of God" circumstances. In our hospital, a specific plan for a telecommunications breakdown did not exist at the time of the incident. Since then, the control command team, led by the head of the emergency department, has undergone multiple training sessions to assess the time needed to gather its members and to test its efficiency in multiple scenarios. The team has also functioned during real incidents, such as the arrival of multiple casualties. Since the telecommunications breakdown in 2007, we have been confronted many times with landline or mobile telecommunications failures, either during maintenance work 
or unannounced incidents. On every occasion, 1 of the 2 telecommunication systems was functional. As a redundant measure during those incidents, we also deployed more security personnel with radios to secure sensitive communications, in particular between rapid response teams, intensive care units, operating rooms, and the emergency department.

When dealing with disasters or major incidents, hospitals mainly focus their training on surge capacity and the arrival of multiple casualties. In-hospital incidents deserve as much attention and training. Testing the control command team operation under internal hospital incidents is easier to organize and not as costly as simulating the arrival of multiple casualties and should be done at least once a year.

\section{About the Authors}

Department of Emergency Medicine (Drs Dami, Carron, Yersin, and Hugli), University Hospital Centre (CHUV), Lausanne, Switzerland.
Correspondence and reprint requests to Fabrice Dami, MD, MBA, Department of Emergency Medicine, Lausanne University Hospital, Bugnon 46, 1011 Lausanne, Switzerland (e-mail: fabrice.dami@chuv.ch)

\section{Acknowledgments}

The description of this case is based on hospital incident reports and interviews with key persons present in the hospital on that night. We thank Stephan Misteli and Jean-Luc Mayor from the information technology department; Laurent Meier from the security department; Mirjam Martinez, registered nurse from the pediatric department; and Dr Bertrand Yersin, head of the emergency department, all of whom were present the night of the incident, for their testimony.

Published online: April 27, 2015.

\section{REFERENCES}

1. Mortelmans L, Van Springel G, Van Boxstael S, et al. Impact of lightning strikes on hospital functions. Prehosp Disaster Med. 2009;24:430-432.

2. Goffion R. Storms: hospitals are not sufficiently protected against lightning strucks. Presented at Hospitals' Engineer Conference; 2013; Paris [in French]. Directhopital.com website. http://www.directhopital. com/Orages-les-hopitaux-peu-proteges-contre-la-foudre-NS_1212.html. Accessed February 2, 2015. 